\title{
High-Speed (Subsecond) Measurement of Heat Capacity, Electrical Resistivity, and Thermal Radiation Properties of Niobium in the Range 1500 to $2700 \mathrm{~K}$ *
}

\author{
Ared Cezairliyan \\ Institute for Materials Research, National Bureau of Standards, Washington, D.C. 20234
}

(August 10, 1971)

\begin{abstract}
Measurements of heat capacity, electrical resistivity, hemispherical total emittance, and normal spectral emittance of niobium in the temperature range 1500 to $2700 \mathrm{~K}$ by a subsecond duration pulse heating technique are described. Results obtained on the above properties are reported and are compared with those in the literature. A sharp increase in heat capacity above $2000 \mathrm{~K}$ was observed. Electrical resistivity showed a negative departure from linearity in the curve of electrical resistivity against temperature. Estimated inaccuracy of measured properties is: 2 percent for heat capacity, 0.5 percent for electrical resistivity, and 3 percent for hemispherical total and normal spectral emittances.
\end{abstract}

Key words: Electrical resistivity; emittance; heat capacity; high-speed measurements; high temperature; niobium; thermal radiation properties; thermodynamics.

\section{Introduction}

Because of the difficulties involved in performing accurate experiments at high temperatures by conventional techniques, a high-speed method was developed to measure heat capacity, electrical resistivity, hemispherical total emittance, and normal spectral emittance of electrical conductors. In this paper, application of this technique to measurements on niobium in the temperature range 1500 to $2700 \mathrm{~K}$ is described.

The method is based on rapid resistive self-heating of the specimen from room temperature to near its melting point. During the short experiment, which lasts less than $1 \mathrm{~s}$, current flowing through the specimen, potential across the specimen and specimen temperature are measured. The experimental quantities are recorded with a digital recording system, which has a time resolution of $0.4 \mathrm{~ms}$, and a full-scale signal resolution of one part in 8000 . Details regarding the construction and operation of the measurement system, the methods of measuring experimental quantities, and other pertinent information, such as formulation of relations for properties, etc. are given in earlier publications $[1,2] .^{1}$

\section{Measurements}

Measurements were performed on two specimens designated as niobium-1 and niobium-2. Each speci-

${ }^{*}$ This work was supported in part by the Directorate of Aeromechanics and Energetics of the U.S. Air Force Office of Scientific Research under contract ISSA-70-0002.

1 Figures in brackets indicate the literature references at the end of this paper. men was a tube of the following nominal dimensions; length, 4 in $(101 \mathrm{~mm})$; outside diameter, 0.25 in $(6.3$ $\mathrm{mm})$; and wall thickness, 0.02 in $(0.5 \mathrm{~mm})$. A small rectangular hole $(0.5 \times 1 \mathrm{~mm})$ fabricated in the wall at the middle of the specimen approximated blackbody conditions for the high-speed photoelectric pyrometer [3].

The measurements were made in the temperature interval 1500 to $2700 \mathrm{~K}$ (approximately $50 \mathrm{~K}$ below the melting point). To optimize the operation of the pyrometer, this temperature interval was divided into six ranges: I, 1500 to $1650 \mathrm{~K}$; II, 1600 to $1800 \mathrm{~K}$; III, 1750 to $1950 \mathrm{~K}$; IV, 1900 to $2200 \mathrm{~K} ; \mathrm{V}, 2100$ to $2550 \mathrm{~K}$; and VI, 2400 to $2700 \mathrm{~K}$.

In each of the first five temperature ranges, two experiments were conducted on niobium-1 and one on niobium-2; in the last range, one experiment was conducted on each specimen. A total of three additional experiments in the ranges II, III, and IV were performed on niobium-1 in which the surface radiance of the specimen was measured.

Before the start of the experiments, each specimen was annealed by subjecting it to 30 heating pulses (up to $2400 \mathrm{~K}$ ). All the experiments were conducted with the specimens in a vacuum environment of approximately $10^{-4}$ torr.

To optimize the operation of the measurement system, the heating rate of the specimens was varied depending on the desired temperature range by adjusting the value of the resistance in series with the specimen. Duration of the current pulses in the experiments ranged from 390 to $450 \mathrm{~ms}$; and the average heating rate of the specimens was approximately 


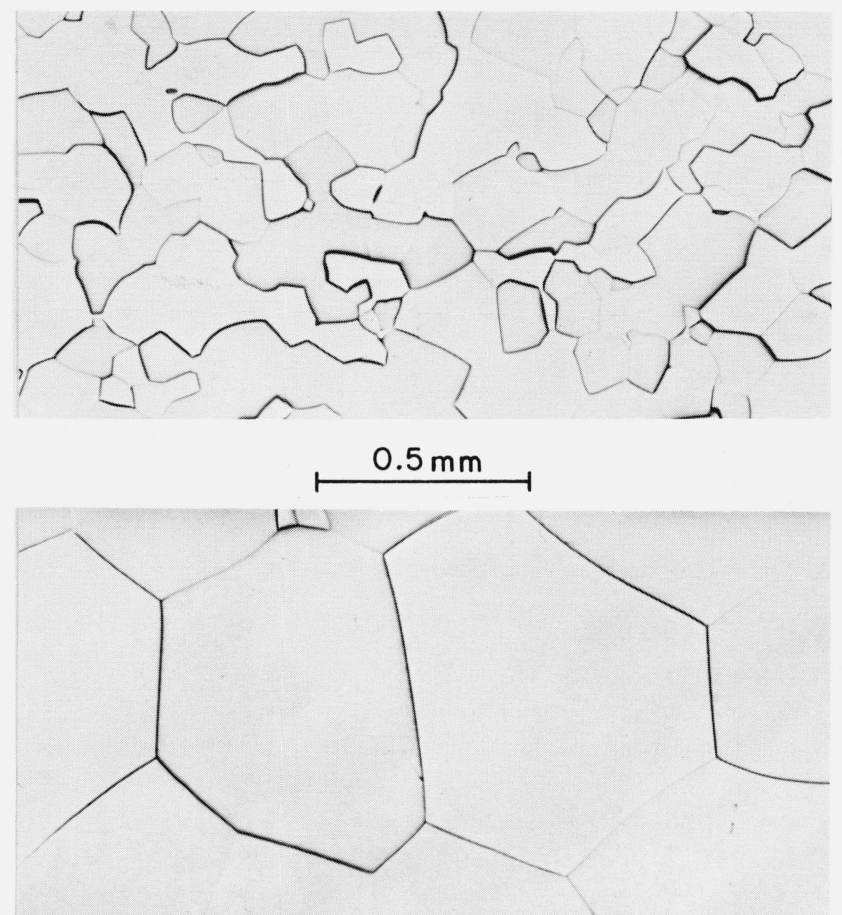

FIgURE 1. Photomicrographs of the niobium specimen before (upper photograph) and after (lower photograph) the entire set of experiments.

$5200 \mathrm{Ks}^{-1}$. Radiative heat losses from the specimens amounted to approximately 1 percent at $1500 \mathrm{~K}$, 3 percent at $2000 \mathrm{~K}$, and 10 percent at $2700 \mathrm{~K}$ of the input power.

Characterization of one of the specimens (niobium-1) was made by the following methods: photomicrography, spectrochemical analysis, and residual resistivity ratio. Photomicrographs of the specimen, shown in figure 1 , indicate that considerable grain growth took place as the result of pulse heating to high temperatures. Chemical analyses were made of the specimen before and after the entire set of experiments. Comparison of results does not indicate any detectable change in impurity concentration. A list of the nature and composition of impurities in the specimen is given in table 1 . The residual resistivity ratio (ratio of electrical resistivity at $273 \mathrm{~K}$ to the residual resistivity) of the specimen, measured before the experiments, was 11.

The data on voltage, current, and temperature were used to obtain third degree polynomial functions for each quantity in terms of time, which then provided the input information for the determination of properties.

\section{Experimental Results}

This section presents the thermophysical properties determined from the measured quantities. All values are based on the International Practical Temperature Scale of 1968 [4]. In all computations, the geometrical quantities are based on their room temperature
(298 K) dimensions. The experimental results are represented by polynomial functions in temperature obtained by least squares approximation of the individual points. The final values on properties at 100 degree temperature intervals computed using the functions are presented in table 2. Results obtained from individual experiments, by the method described previously [2], are given in the appendix (tables A-1, $\mathrm{A}-2$, and $\mathrm{A}-3$ ).

\subsection{Heat Capacity}

Heat capacity was computed from data taken during the heating period. A correction for power loss due to thermal radiation was made using the results on hemispherical total emittance. The standard deviation of the individual data points from a third degree polynomial function in the range 1500 to $2700 \mathrm{~K}$ for each specimen is 0.7 percent for niobium- 1 and 0.9 percent for niobium-2. The average absolute difference between the results on two specimens is 0.7 percent. The function for heat capacity (standard deviation= $0.8 \%$ ) that represents the combined results of the two specimens in the temperature interval 1500 to $2700 \mathrm{~K}$ is:

$c_{p}=-3.395+4.855 \times 10^{-2} T-2.531 \times 10^{-5} T^{2}$

$$
+5.035 \times 10^{-9} T^{3}
$$

where $T$ is in $\mathrm{K}$ and $c_{p}$ is in $\mathrm{J} \mathrm{mol}^{-1} \mathrm{~K}^{-1}$. In the computations of heat capacity, the atomic weight of niobium was taken as 92.91 .

\subsection{Electrical Resistivity}

The electrical resistivity of niobium was determined from the same experiments that were used to calculate heat capacity. The standard deviation of the individual data points from a second degree polynomial function in the range 1500 to $2700 \mathrm{~K}$ for each specimen is 0.2 percent for both niobium-1 and niobium-2. The average absolute difference between the results on two specimens is 0.5 percent. The function for electrical resistivity (standard deviation $=0.3 \%$ ) that represents

TABLE 1. Impurities in niobium specimen

\begin{tabular}{c|r||c|r}
\hline \hline Impurity & $\begin{array}{c}\text { Amount } \\
\text { ppm }\end{array}$ & Impurity & $\begin{array}{c}\text { Amount } \\
\text { ppm }\end{array}$ \\
\hline $\mathrm{Al}$ & 5 & $\mathrm{Mo}$ & 5 \\
$\mathrm{As}$ & $<5$ & $\mathrm{Ni}$ & $<1$ \\
$\mathrm{~B}$ & $<1$ & $\mathrm{~Pb}$ & $<1$ \\
$\mathrm{Bi}$ & $<5$ & $\mathrm{Sb}$ & $<10$ \\
$\mathrm{Ca}$ & $<1$ & $\mathrm{Si}$ & $<5$ \\
$\mathrm{Cd}$ & $<5$ & $\mathrm{Sn}$ & 3 \\
$\mathrm{Co}$ & $<1$ & $\mathrm{Ta}$ & 450 \\
$\mathrm{Cr}$ & $<1$ & $\mathrm{Te}$ & $<5$ \\
$\mathrm{Cu}$ & $<1$ & $\mathrm{Ti}$ & $<1$ \\
$\mathrm{Fe}$ & $<3$ & $\mathrm{~V}$ & $<1$ \\
$\mathrm{Hf}$ & $<50$ & $\mathrm{~W}$ & $<100$ \\
$\mathrm{Mg}$ & $<1$ & $\mathrm{Zn}$ & $<10$ \\
$\mathrm{Mn}$ & $<1$ & $\mathrm{Zr}$ & $<5$ \\
\hline
\end{tabular}

$470<$ Total $<680$ 
TABLE 2. Heat capacity, electrical resistivity, hemispherical total emittance and normal spectral emittance of niobium

\begin{tabular}{c|c|c|c|c}
\hline \hline $\begin{array}{c}\text { Temp. } \\
\mathrm{K}\end{array}$ & $\begin{array}{c}c_{p} \\
\mathrm{~J} \mathrm{~mol}^{-1} \mathrm{~K}^{-1}\end{array}$ & $\begin{array}{c}\rho^{a} \\
10^{-\times} \boldsymbol{n}_{\mathrm{n}}\end{array}$ & $\epsilon^{a}$ & $\epsilon_{i, \lambda}$ \\
\hline 1500 & 29.48 & 57.58 & & \\
1600 & 30.11 & 60.41 & & \\
1700 & 30.73 & 63.20 & 0.217 & 0.353 \\
1800 & 31.35 & 65.96 & .230 & .352 \\
1900 & 32.02 & 68.68 & .242 & .352 \\
2000 & 32.75 & 71.37 & .254 & .351 \\
2100 & 33.57 & 74.02 & .264 & .351 \\
2200 & 34.53 & 76.63 & .274 & .351 \\
2300 & 35.64 & 79.20 & .282 & .350 \\
2400 & 36.94 & 81.74 & .290 & \\
2500 & 38.46 & 84.25 & .297 & \\
2600 & 40.23 & 86.71 & .303 & \\
2700 & 42.28 & 89.14 & & \\
\hline
\end{tabular}

${ }^{a}$ Based on ambient temperature (298 K) dimensions

the combined results of the two specimens in the temperature interval 1500 to $2700 \mathrm{~K}$ is:

$$
\rho=10.74+3.396 \times 10^{-2} \boldsymbol{T}-1.823 \times 10^{-6} \boldsymbol{T}^{2}
$$

where $T$ is in $\mathrm{K}$, and $\rho$ is in $10^{-8} \Omega \mathrm{m}$. In the computations of the specimen's cross-sectional area, which is needed for the computations of electrical resistivity, the density of niobium was taken as $8.57 \times 10^{3} \mathrm{~kg} \mathrm{~m}^{-3}$ [5]. The measurements, before pulse experiments, of the electrical resistivity of the two niobium specimens at $293 \mathrm{~K}$ with a Kelvin bridge were in agreement within 0.1 percent. Electrical resistivity of niobium at $293 \mathrm{~K}$ obtained by averaging the results of the two specimens is $15.9 \times 10^{-8} \Omega \mathrm{m}$.

\subsection{Hemispherical Total Emittance}

Hemispherical total emittance was computed for niobium-1 using data taken during both heating and initial free cooling periods. The function for hemispherical total emittance ( standard deviation $=0.4 \%$ ) that represents the results in the temperature range 1700 to $2650 \mathrm{~K}$ is:

$$
\epsilon=-0.144+2.88 \times 10^{-4} T-4.46 \times 10^{-8} T^{2}
$$

where $T$ is in $\mathrm{K}$.

\subsection{Normal Spectral Emittance}

Normal spectral emittance was computed for niobium-1 using data from three sets of two experiments, one in which the pyrometer was aimed at the surface of the specimen, and another in which it was aimed at the blackbody hole in the specimen. The measurements were made at the effective wavelength of the pyrometer interference filter $(650 \mathrm{~nm}$; bandwidth $10 \mathrm{~nm}$ ). The function for normal spectral emittance (standard deviation $=0.6 \%$ ) that represents the results in the temperature range 1700 to $2300 \mathrm{~K}$ is:

$$
\epsilon_{N, \lambda}=0.361-4.77 \times 10^{-6} T
$$

where $T$ is in $\mathrm{K}$.

\section{Estimate of Errors}

Estimates of errors in measured and computed quantities lead to the following estimates of errors in the properties over the temperature range 1500 to $2700 \mathrm{~K}$ : heat capacity, 2 percent; electrical resistivity, 0.5 percent; hemispherical total emittance, 3 percent; normal spectral emittance, 3 percent. Details regarding the estimates of errors and their combination in highspeed experiments using the present measurement system are given in a previous publication [2]. Specific items in the error analysis were recomputed whenever the present conditions differed from those in the earlier publication.

In all the earlier experiments with the present highspeed system, the lowest temperature at which measurements were made was $1900 \mathrm{~K}$. In the present work, the measurements were extended down to $1500 \mathrm{~K}$ without creating any significant uncertainties in temperature measurements. The imprecision ${ }^{2}$ of temperature measurements was $0.7 \mathrm{~K}$ at $1500 \mathrm{~K}$, and $0.5 \mathrm{~K}$ at $1900 \mathrm{~K}$. The imprecision of voltage and current measurements was less than 0.02 and 0.03 percent, respectively, over the entire temperature range.

\section{Discussion}

The heat capacity and electrical resistivity results of this work are compared graphically with those in the literature in figures 2 and 3 , respectively. Numerical comparisons are given in tables 3 and 4 . Heat capacity results of this work are, in general, lower than those of most other investigators, with the exception of Kraftmakher [8]. Electrical resistivity results are in good agreement with those of others. Estimates of errors in papers cited lead to an estimate of inaccuracies in previously reported heat capacity and electrical resistivity of approximately 5 to 10 and 1 to 3 percent, respectively.

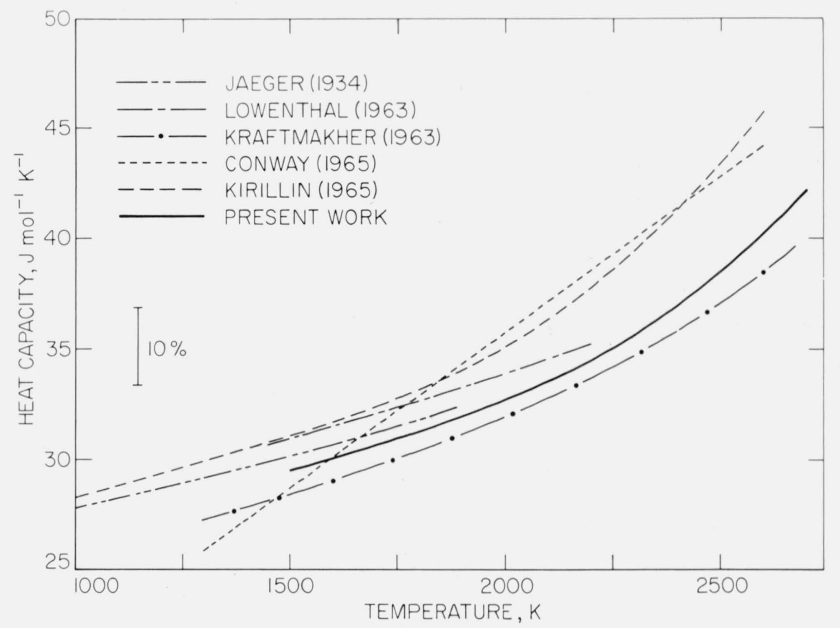

FIGURE 2. Heat capacity of niobium reported in the literature.

${ }^{2}$ Imprecision refers to the standard deviation of an individual point as computed from the difference between measured value and that from the smooth function obtained by the least squares method. 


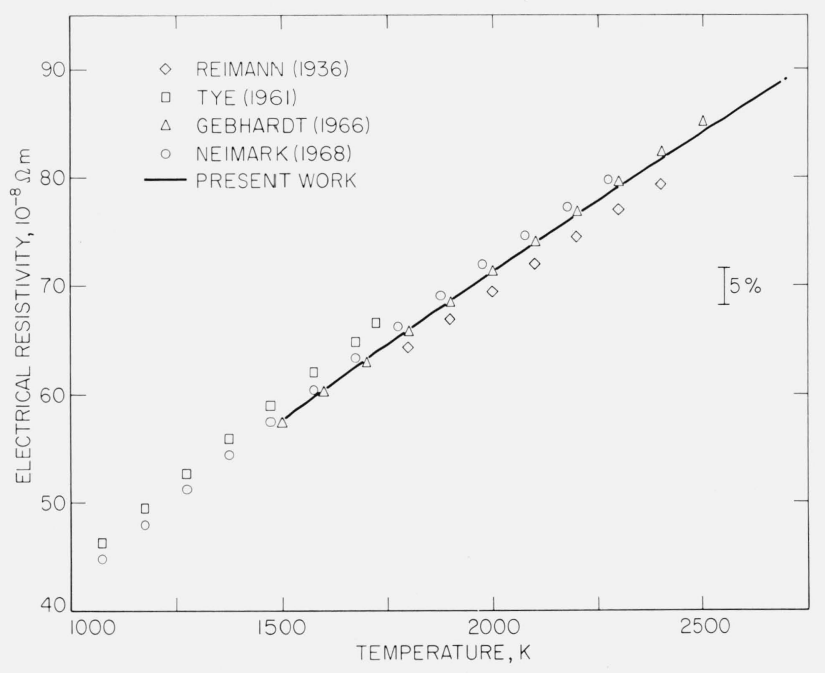

FIGURE 3. Electrical resistivity of niobium reported in the literature.

The present result of the electrical resistivity of niobium corresponding to $293 \mathrm{~K}$ is $15.9 \times 10^{-8} \Omega \mathrm{m}$; those reported in the recent literature range from $14.6 \times 10^{-8} \Omega \mathrm{m}[13]$ to $16.9 \times 10^{-8} \Omega \mathrm{m}[12]$.

The results for hemispherical total emittance and normal spectral emittance of this work and those in the literature are presented in figures 4 and 5 , respectively. Deviations in the results of various investigators may largely be attributed to the differences in specimen surface conditions.

Similar to the earlier results on molybdenum [2], tantalum [21], and tungsten [22] obtained with the present measurement system, heat capacity of niobium at high temperatures is considerably higher than the Dulong and Petit value of $3 R$. Some of this departure is due to $c_{p}-c_{v}$ and the electronic terms. However, they do not account for the entire difference. Heat capacity above the Debye temperature may be expressed by

$$
c_{p}=A-\frac{B}{T^{2}}+C T+\Delta c
$$

where the constant term is $3 \mathrm{R}\left(24.943 \mathrm{~J} \mathrm{~mol}^{-1} \mathrm{~K}^{-1}\right)$, the term in $T^{-2}$ is the first term in the expansion of the Debye function, the term in $T$ represents $c_{p}-c_{v}$ and electronic contributions, and the quantity $\Delta c$ represents excess in measured heat capacity at high temperatures, which is not accounted for by the first three terms. The coefficients $B\left(9.6 \times 10^{4}\right)$ and $C\left(2.9 \times 10^{-3}\right)$ were obtained from data on heat capacity at $200 \mathrm{~K}$ and $1000 \mathrm{~K}$ given by Hultgren et al. [23].

Using eq (5) and the heat capacity results of this work, the quantity $\Delta c$ was computed for temperatures above $1500 \mathrm{~K}$. The results for $\Delta c$ in $\mathrm{J} \mathrm{mol}^{-1} \mathrm{~K}^{-1}$ are: 0.2 at $1500 \mathrm{~K}, 2.0$ at $2000 \mathrm{~K}, 6.3$ at $2500 \mathrm{~K}$, and 9.5 at $2700 \mathrm{~K}$.

Although the mechanisms of vacancy generation become important at high temperatures, it was not possible to attribute the high heat capacity values entirely to vacancies. To demonstrate this, a crude estimate of the contribution of vacancies to heat capacity was made using the method described in a previous publication [2]. The results indicate that vacancy contribution would be small, less than $0.05 \mathrm{~J}$ $\mathrm{mol}^{-1} \mathrm{~K}^{-1}$ at $2000 \mathrm{~K}$ and $0.5 \mathrm{~J} \mathrm{~mol}^{-1} \mathrm{~K}^{-1}$ at $2700 \mathrm{~K}$, and would not account for the high heat capacity values. If the entire difference between measured and computed [using the first three terms in eq (5)] heat capacities is attributed to vacancies, values of $1.3 \mathrm{eV}$ for vacancy formation energy and 3.5 percent for vacancy concentration at the melting point are obtained. Both of these values seem to be unrealistic for niobium.

To give a simple expression for the heat capacity of niobium over a wide temperature range, an empirical term for the quantity $\Delta c$ in eq (5) was substituted. Trials indicated that a term in $T^{5}$ describes the experimental results better than a term in $T^{4}$. The coefficient of this term was obtained from the results of the present work in conjunction with the values given by Hultgren et al. [23] at temperatures below $1000 \mathrm{~K}$. Then eq (5) for the range 300 to $2700 \mathrm{~K}$ becomes

$c_{p}=24.943-\frac{9.6 \times 10^{4}}{T^{2}}+2.9 \times 10^{-3} T+6.4 \times 10^{-17} T^{5}$

where $T$ is in $\mathrm{K}$ and $c_{p}$ is in $\mathrm{J} \mathrm{mol}^{-1} \mathrm{~K}^{-1}$. Average absolute deviation of the individual points from the function over the temperature range considered is 0.4 percent. Equation (6) is presented graphically in figure 6.

TABLE 3. Niobium heat capacity difference (previous literature minus present work values) in percent

\begin{tabular}{l|c|c|c|c|c|c|c|c|c|c}
\hline \hline \multirow{2}{*}{ Investigator } & \multirow{2}{*}{ Ref. } & \multirow{2}{*}{ Year } & \multirow{2}{*}{ Method } & \multicolumn{7}{c}{ Temperature, K } \\
\cline { 5 - 10 } & & & & 1500 & 1700 & 1900 & 2100 & 2300 & 2500 & 2700 \\
\hline Jaeger and Veenstra & 6 & 1934 & drop & +2.4 & +1.8 & +1.3 & & & & \\
Lowenthal & 7 & 1963 & modul. & +4.8 & +4.1 & +3.6 & +2.6 & +0.7 & & \\
Kraftmakher & 8 & 1963 & modul. & -3.6 & -3.4 & -3.1 & -2.9 & -3.2 & -4.0 & -5.5 \\
Conway and Hein & 9 & 1965 & drop & -2.6 & +2.6 & +7.2 & +10.6 & +12.0 & +11.0 & \\
Kirillin et al. & 10 & 1965 & drop & +5.2 & +5.1 & +6.3 & +8.2 & +10.4 & +12.3 & +13.6 \\
\hline
\end{tabular}


TABLE 4. Niobium electrical resistivity difference (previous literature minus present work values) in percent

\begin{tabular}{l|r|r|r|r|r|r|r|r}
\hline \hline \multirow{2}{*}{ Investigator } & Ref. & Year & \multicolumn{6}{|c}{ Temperature, K } \\
\cline { 4 - 8 } & 11 & 1936 & & & -2.7 & -2.8 & -2.9 & \\
\hline Reiman & 12 & 1961 & +3.6 & +3.9 & & & & \\
Tye & 13 & 1966 & -0.6 & -0.6 & -0.5 & -0.1 & +0.4 & +1.0 \\
Gebhardt et al. & & & & & & & & \\
$\begin{array}{c}\text { Neimark and } \\
\text { Voronin }\end{array}$ & 14 & 1968 & +1.0 & +1.4 & +1.6 & +1.7 & +1.6 & \\
\hline
\end{tabular}

Earlier work on tantalum [21], which also belongs to Group $\mathrm{V}$, indicated that the quantity $\Delta c$ in eq (5) is best represented by a term in $T^{5}$. However, the results on molybdenum [2] and tungsten [22], which belong to Group VI, indicated that the same quantity is best described by a term in $T^{4}$. The significance of this is not apparent at this time.

Electrical resistivity of niobium, in the range of present measurements, showed a negative departure from linearity in the curve of electrical resistivity

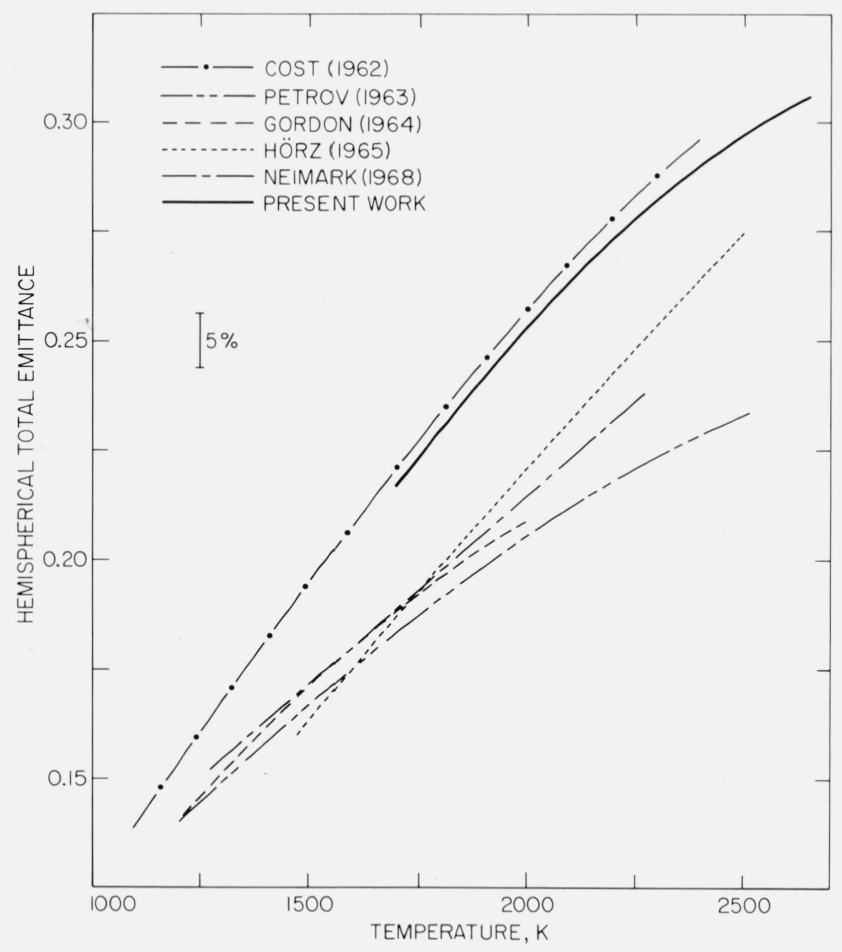

FigURE 4. Hemispherical total emittance of niobium reported in the literature.

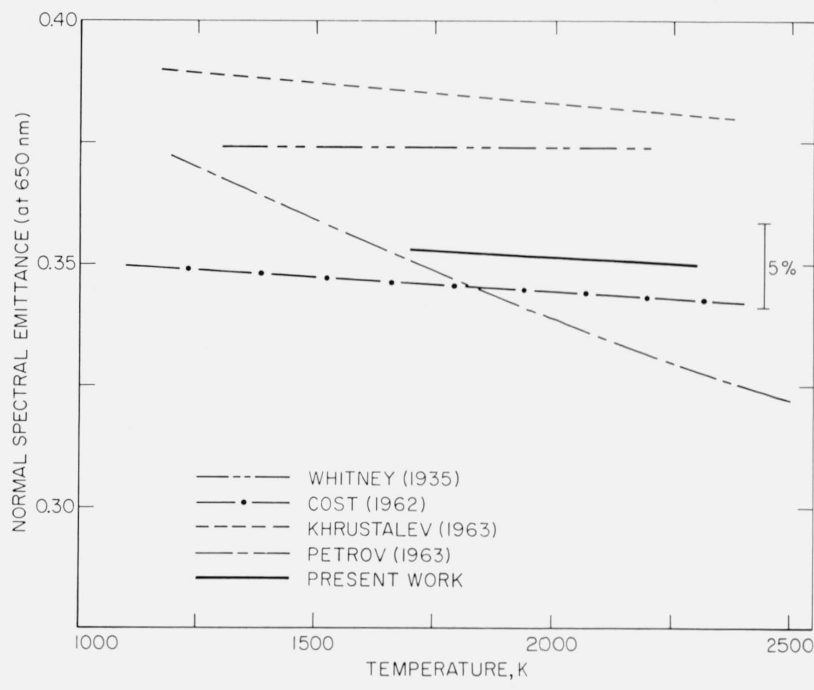

FIGURE 5. Normal spectral emittance of nibium at $\lambda=650 \mathrm{~nm}$ reported in the literature.

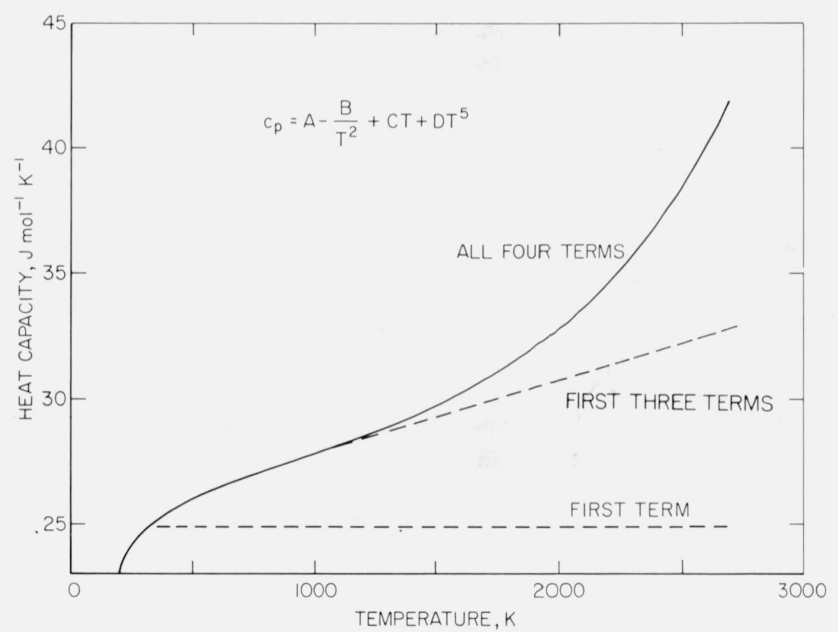

Figure 6. Heat capacity of niobium according to equation (6).

against temperature. A similar trend was also observed for tantalum [21].

The author expresses his gratitude to C. W. Beckett for his continued interest and encouragement of research in high-speed methods of measuring thermophysical properties. The contributions of M. S. Morse in connection with electronic instrumentation are also greatly appreciated. 


\section{Appendix}

TABLE A-1. Experimental results on heat capacity and electrical resistivity of niobium ${ }^{a}$

\begin{tabular}{|c|c|c|c|c|c|c|c|}
\hline \multirow{3}{*}{ Range } & \multirow{3}{*}{$\begin{array}{c}\text { Specimen } \\
\text { Run } \\
T\end{array}$} & \multicolumn{4}{|c|}{ Niobium-1 } & \multirow{2}{*}{\multicolumn{2}{|c|}{$\frac{\text { Niobium-2 }}{1}$}} \\
\hline & & \multicolumn{2}{|c|}{1} & \multicolumn{2}{|c|}{2} & & \\
\hline & & $c_{p}$ & $\rho$ & $c_{p}$ & $\rho$ & $c_{p}$ & $\rho$ \\
\hline \multirow[t]{4}{*}{ I } & 1500 & 29.56 & 57.48 & 29.39 & 57.49 & 29.51 & 57.82 \\
\hline & 1550 & 29.72 & 58.89 & 29.69 & 58.89 & 30.05 & 59.22 \\
\hline & 1600 & 30.11 & 60.28 & 30.14 & 60.28 & 30.58 & 60.63 \\
\hline & 1650 & 30.74 & 61.67 & 30.75 & 61.67 & 31.09 & 62.04 \\
\hline \multirow[t]{5}{*}{ II } & 1600 & 29.87 & 60.34 & 29.99 & 60.35 & 29.99 & 60.71 \\
\hline & 1650 & 30.15 & 61.71 & 30.22 & 61.72 & 30.47 & 62.08 \\
\hline & 1700 & 30.52 & 63.09 & 30.55 & 63.09 & 30.93 & 63.46 \\
\hline & 1750 & 31.01 & 64.45 & 31.01 & 64.44 & 31.39 & 64.83 \\
\hline & 1800 & 31.60 & 65.80 & 31.59 & 65.81 & 31.83 & 66.19 \\
\hline \multirow[t]{5}{*}{ III } & 1750 & 30.65 & 64.48 & 30.55 & 64.48 & 30.85 & 64.86 \\
\hline & 1800 & 31.03 & 65.83 & 31.07 & 65.81 & 31.29 & 66.20 \\
\hline & 1850 & 31.48 & 67.16 & 31.59 & 67.15 & 31.78 & 67.55 \\
\hline & 1900 & 32.00 & 68.50 & 32.11 & 68.49 & 32.31 & 68.89 \\
\hline & 1950 & 32.61 & 69.83 & 32.62 & 69.82 & 32.90 & 70.24 \\
\hline \multirow[t]{7}{*}{ IV } & 1900 & 31.91 & 68.59 & 31.66 & 68.61 & 31.69 & 69.01 \\
\hline & 1950 & 32.19 & 69.92 & 32.07 & 69.92 & 32.22 & 70.33 \\
\hline & 2000 & 32.55 & 71.23 & 32.53 & 71.23 & 32.76 & 71.64 \\
\hline & 2050 & 32.98 & 72.54 & 33.03 & 72.54 & 33.33 & 72.95 \\
\hline & 2100 & 33.50 & 73.83 & 33.58 & 73.84 & 33.93 & 74.25 \\
\hline & 2150 & 34.12 & 75.12 & 34.19 & 75.14 & 34.56 & 75.55 \\
\hline & 2200 & 34.87 & 76.42 & 34.85 & 76.43 & 35.23 & 76.84 \\
\hline \multirow[t]{10}{*}{ V } & 2100 & 33.58 & 73.98 & 33.37 & 73.98 & 33.61 & 74.37 \\
\hline & 2150 & 34.00 & 75.27 & 33.87 & 75.27 & 34.10 & 75.66 \\
\hline & 2200 & 34.46 & 76.55 & 34.41 & 76.55 & 34.62 & 76.94 \\
\hline & 2250 & 34.97 & 77.83 & 34.97 & 77.82 & 35.18 & 78.21 \\
\hline & 2300 & 35.53 & 79.09 & 35.58 & 79.08 & 35.79 & 79.47 \\
\hline & 2350 & 36.16 & 80.35 & 36.24 & 80.34 & 36.46 & 80.72 \\
\hline & 2400 & 36.86 & 81.60 & 36.96 & 81.59 & 37.19 & 81.97 \\
\hline & 2450 & 37.66 & 82.84 & 37.75 & 82.83 & 38.01 & 83.21 \\
\hline & 2500 & 38.57 & 84.07 & 38.62 & 84.06 & 38.91 & 84.45 \\
\hline & 2550 & 39.63 & 85.29 & 39.60 & 85.30 & 39.94 & 85.69 \\
\hline \multirow[t]{7}{*}{ VI } & 2400 & 36.73 & 81.69 & & & 37.01 & 82.08 \\
\hline & 2450 & 37.21 & 82.92 & & & 37.39 & 83.31 \\
\hline & 2500 & 37.85 & 84.13 & & & 37.98 & 84.53 \\
\hline & 2550 & 38.68 & 85.34 & & & 38.82 & 85.74 \\
\hline & 2600 & 39.74 & 86.54 & & & 39.99 & 86.94 \\
\hline & 2650 & 41.10 & 87.75 & & & 41.60 & 88.15 \\
\hline & 2700 & 42.89 & 88.97 & & & 43.21 & 89.37 \\
\hline
\end{tabular}

a Temperature in $\mathrm{K}$. heat capacity in $\mathrm{J} \mathrm{mol}^{-1} \mathrm{~K}^{-1}$. electrical resistivity in $10^{-8} \Omega \mathrm{m}$. 
TABLE A-2. Experimental results on hemispherical total emittance of niobium-1

\begin{tabular}{c|r}
\hline \hline$T$ & $\epsilon$ \\
$\mathrm{K}$ & \\
\hline 1715 & 0.219 \\
1715 & .217 \\
1715 & .220 \\
1714 & .218 \\
1890 & .240 \\
1889 & .239 \\
1889 & .243 \\
1889 & .242 \\
2058 & .261 \\
2057 & .260 \\
2057 & .260 \\
2056 & .259 \\
2328 & .286 \\
2326 & .284 \\
2326 & .284 \\
2325 & .283 \\
2655 & .307 \\
2653 & .307 \\
2653 & .306 \\
2651 & .305 \\
\hline
\end{tabular}

TABLE A-3. Experimental results on normal spectral emittance of niobium-1 at $\lambda=650 \mathrm{~nm}$

\begin{tabular}{c|c}
\hline \hline$T$ & $\epsilon_{N, \lambda}$ \\
$\mathrm{K}$ & \\
\hline 1694 & 0.354 \\
1712 & .354 \\
1730 & .353 \\
1747 & .353 \\
1765 & .353 \\
1783 & .353 \\
1801 & .353 \\
1818 & .354 \\
1836 & .354 \\
1853 & .349 \\
1874 & .349 \\
1895 & .349 \\
1916 & .350 \\
1937 & .351 \\
1957 & .352 \\
1978 & .353 \\
1998 & .354 \\
2019 & .355 \\
2038 & .350 \\
2069 & .348 \\
2099 & .348 \\
2129 & .348 \\
2158 & .349 \\
2187 & .349 \\
2216 & .350 \\
2244 & .352 \\
2272 & .353 \\
2300 & .354 \\
\hline
\end{tabular}

\section{References}

[1] Cezairliyan, A., Design and operational characteristics of a high-speed (millisecond) system for the measurement of thermophysical properties at high temperatures. J. Res. Nat. Bur. Stand. (U.S.) 75C (Eng. and Instr), No. 1, 7 (1971).
[2] Cezairliyan, A., Morse, M. S., Berman, H. A., and Beckett, C. W., High-speed (subsecond) measurement of heat capacity. electrical resistivity, and thermal radiation properties of molybdenum in the range 1900 to $2800 \mathrm{~K}$, J. Res. Nat. Bur. Stand. (U.S.) 74A (Phys. and Chem.), No. 1, 65 (1970).

[3] Foley, G. M., High-speed optical pyrometer, Rev. Sci. Instr. 41, 827 (1970).

[4] International Practical Temperature Scale of 1968, Metrologia 5, 35 (1969).

[5] Tietz, T. E. and Wilson, J. W., Behavior and properties of refractory metals, p. 28. (Stanford University Press, California, 1965).

[6] Jaeger, F. M., and Veenstra, W. A., The exact measurement of the specific heats of solid substances at high temperatures. VI, the specific heats of vanadium, niobium, tantalum, and molybdenum. Rec. Trav. Chim. 53, 677 (1934).

[7] Lowenthal, G. C., The specific heat of metals between $1200 \mathrm{~K}$ and $2400 \mathrm{~K}$, Australian J. Phys. 16, 47 (1963).

[8] Kraftmakher, Ya. A., Vacancy formation in niobium. Solid State (USSR), 5, 696 (1963).

[9] Conway, J. B., and Hein, R. A., Enthalpy measurements of solid materials to $2400 \mathrm{C}$ by means of drop technique in advances in thermophysical properties at extreme temperatures and pressures, S. Gratch, ed., p. 131. (ASME, New York 1965).

[10] Kirillin, V. A., Sheindlin, A. E., Chekhovskoi, V. Ya., and Zhukova, I. A., Experimental determination of the enthalpy of niobium in the temperature range 600 to $2600 \mathrm{~K}$. High Temperature, 3, 357 (1965).

[11] Reimann, A. L., Some high-temperature properties of niobium. Phil. Mag. 22, 34 (1936).

[12] Tye, R. P.. Preliminary measurements on the thermal and elec trical conductivities of molybdenum, niobium, tantalum, and tungsten, J. Less-Common Metals 3, 13 (1961).

[13] Gebhardt, E., Dürrschnabel, W.. and Hörz, G., J. Nucl. Mat. 18, 119 (1966).

[14] Neimark, B. E., and Voronin, L. K., Thermal conductivity, specific electrical resistivity, and total emissivity of refractory metals at high temperatures, High Temperature 6 , 999 (1968).

[15] Cost, J. R., Emissivities of niobium and niobium-nitrogen solids solutions, Trans. Metall. Soc. AIME 224, 634 (1962).

[16] Petrov, V. A., Chekhovskoi, V. Ya., and Sheindlin, A. E. Experimental determination of the degree of blackness of niobium at temperatures of 1200 to $2500 \mathrm{~K}$, High Tempera ture 1, 416 (1963).

[17] Gordon, A. R., and Muchnik, G. F., Determination of the emissivity of niobium as a function of the roughness of the surface, High Temperature 2, 505 (1964).

[18] Hörz, G., Dürrschnabel, W., and Gebhardt, E., Hemispherical total emittance of niobium, J. Nucl. Mat. 17, 277 (1965).

[19] Whitney, L. V., The temperature scales of columbium, thor ium, rhodium and molybdenum at $0.667 \mu$, Phys. Rev. 48, 458 (1935).

[20] Khrustalev, B. A., Kolchenogova, I. P., and Rakov, A. M. Spectral coefficients of tantalum, molybdenum and niobium radiation, High Temperature 1, 13 (1963).

[21] Cezairliyan, A., McClure, J. L., and Beckett, C. W., High speed (subsecond) measurement of heat capacity, electrical resistivity, and thermal radiation properties of tantalum in the range 1900 to $3200 \mathrm{~K}$, J. Res. Nat. Bur. Stand. (U.S.) 75A (Phys. and Chem.), No. 1, l (1971).

[22] Cezairliyan, A., and McClure, J. L., High-speed (subsecond) measurement of heat capacity, electrical resistivity, and thermal radiation properties of tungsten in the range 2000 to 3600 K, J. Res. Nat. Bur. Stand. (U.S.), 75A (Phys. and Chem.), No. 4, 283 (1971).

[23] Hultgren, R., Orr, R. L., Anderson, P. D., and Kelly, K. K. Selected Values of Thermodynamic Properties of Metals and Alloys, (Wiley, New York, 1963). 